\title{
Sensitivity of tropical cyclones to convective parameterization schemes in RegCM4
}

Article

Accepted Version

Villafuerte II, M. Q., Lambrento, J. C. R., Hodges, K. I., Cruz, F. T., Cinco, T. A. and Narisma, G. T. (2021) Sensitivity of tropical cyclones to convective parameterization schemes in RegCM4. Climate Dynamics, 56. pp. 1625-1642. ISSN 09307575 doi: https://doi.org/10.1007/s00382-020-05553-3 Available at https://centaur.reading.ac.uk/94535/

It is advisable to refer to the publisher's version if you intend to cite from the work. See Guidance on citing.

To link to this article DOI: http://dx.doi.org/10.1007/s00382-020-05553-3

Publisher: Springer

All outputs in CentAUR are protected by Intellectual Property Rights law, including copyright law. Copyright and IPR is retained by the creators or other copyright holders. Terms and conditions for use of this material are defined in the End User Agreement.

www.reading.ac.uk/centaur 
Central Archive at the University of Reading

Reading's research outputs online 


\section{Sensitivity of tropical cyclones to convective parameterization}

\section{schemes in RegCM4}

3

4

5

6

$19 *$ Correspondence to:

20 Marcelino Q. Villafuerte II

21 DOST-PAGASA, BIR Road, Brgy. Central, Quezon City 1100, Philippines

22 Telefax: +632-3434-2698

23 Email: mvillafuerte@ pagasa.dost.gov.ph

24 ORCID: https://orcid.org/0000-0002-1620-4935 


\section{Abstract}

This study investigates the sensitivity of simulated tropical cyclones (TC) affecting the

27 Philippines to convective parameterization schemes (CPS) in the Regional Climate Model

28 Version 4 (RegCM4). Five ERA-Interim driven RegCM4 simulations at 25-km resolution were

29 conducted utilizing the CPS of Grell with Arakawa-Schubert closure (GR), Emanuel (EM),

30 Kain-Fritsch (KF), Tiedtke (TE), and a combined Grell scheme over land and Emanuel over

31 ocean (GR-EM). Comparisons between observed and modelled TCs covering a 30-year period

32 (1981-2010) indicate that the EM scheme yields an annual-mean TC frequency that is closest to

33 observations. The GR-EM scheme, on the other hand, closely reproduces the observed seasonal

34 patterns of TC tracks, spatial patterns of TC track density and TC-associated rainfall, and TC

35 lifespan over the PAR. The KF scheme is the only CPS that was able to simulate intense TCs

36 (maximum wind speed $>40 \mathrm{~m} \mathrm{~s}^{-1}$ ) within the domain. In contrast, both GR and TE schemes

37 largely underestimated the TC frequency, and were only able to simulate weak TCs (maximum

38 wind speed $<17 \mathrm{~m} \mathrm{~s}^{-1}$ ). Such underestimation in the TC frequency and intensity in the GR and

39 TE simulations can be attributed to the dry mid-tropospheric environment and the absence of a

40 large area with positive low-level relative vorticity over the Pacific Ocean, which inhibit TC

41 formation and further development over the area. These findings will be helpful in deciding

42 which CPS is more appropriate to use in conducting TC-related model simulations in the context

43 of the Philippine domain.

44

45

46 Keywords: regional climate modeling, sensitivity experiments, tropical cyclones, western North

47 Pacific, the Philippines 


\section{Introduction}

49 The Philippines is highly exposed to natural hazards such as tropical cyclones (TC) due to

50 its geographic location. The country is situated in the western North Pacific (WNP) basin, where

51 environmental conditions for TC formation are optimal. An assessment of TC data from 1951 to

522013 shows that, on average, 9 out of 19 TCs entering the Philippine Area of Responsibility

53 (PAR; enclosed by the dashed lines in Fig. 1) make landfall over the country annually (Cinco et

54 al. 2016). These TCs can have disastrous impacts, and the economic losses due to TCs from

551970 to 2009 have been estimated at \$6.2 billion (Gupta 2010). Furthermore, an annual

56 increasing trend in TC-associated economic loss and damage has been observed over recent

57 years (Lansigan et al. 2000; Blanc and Strobl 2016; Cinco et al. 2016; Bagtasa 2017). The

58 projected increase in occurrence of more intense TCs in the future (e.g., Gallo et al. 2019),

59 highlights the need for further understanding of TCs, including the ability (or inability) of

60 climate models to simulate their different characteristics in order to have confidence in model

61 projections.

62 Global climate models (GCMs) are useful for investigating the climate system, including

63 possible future changes in TC activity (e.g., Bengtsson et al. 2007; Sugi et al. 2009; Tang and

64 Camargo 2014). However, multi-decadal simulations using GCMs generally have coarse

65 horizontal resolutions (typically between 100 and $300 \mathrm{~km}$ ) because of the vast computational

66 resources needed to run the models, and thus have been found to be unable to simulate all

67 characteristics of TCs well (Strachan et al. 2013). While such limitations of GCMs have been

68 addressed recently because of computational advancements and concerted efforts shared by

69 scientists (e.g., Haarsma et al. 2016), conducting long-term high-resolution model simulations

70 using GCMs remains a big challenge for most institutes in developing countries with insufficient 
71 infrastructure. In turn, regional climate models (RCMs), which only need modest computing

72 resources, are widely used to complement GCMs, particularly for resolving processes important

73 at smaller spatial scales (e.g., Giorgi and Gutowski 2015). For instance, Jin et al. (2016) used a

74 number of RCMs to investigate the present day TC climatology and obtained more credible and

75 reliable estimates of future TC activity over the WNP. RCMs have also been used to provide

76 high-resolution future projections of TC activity over the Central America (Diro et al. 2014),

77 Vietnam (Wang et al. 2017), as well as in the Philippines (Gallo et al. 2019).

78 Although high-resolution model simulations have been achieved with the aid of RCMs,

79 many sub-grid scale processes are still parameterized in the RCMs, particularly for simulations

80 with horizontal resolutions $>5 \mathrm{~km}$ (e.g., Fuentes-Franco et al. 2017; Shen et al. 2019). In a

81 number of studies, it has been demonstrated that the convective parameterization plays an

82 important role in capturing various TC characteristics including their development (Pattanayak et

83 al. 2012), subsequent tracks (Prater and Evans 2002; Rao and Prasad 2007; Pattanayak et al.

84 2012; Sun et al. 2015), intensity (Knutson and Tuleya 2004; Kanada et al. 2012; Biswas et al.

85 2014), and frequency (e.g., Yoshimura et al. 2006; Zhao et al. 2012). Nevertheless, different

86 results have been obtained from studies that have investigated the sensitivity of TCs to

87 convective parameterization schemes (CPS). For instance, Mohandas and Ashrit (2014) have

88 used the Weather Research and Forecasting (WRF) model, and showed that the Kain-Fritsch

89 scheme reproduced the observed track and structure of TCs over the Indian Ocean more

90 accurately than the other CPS. In another study, simulations of TCs using RegCM4 over the

91 Central American Coordinated Regional Climate Downscaling Experiment (CORDEX) domain

92 showed that the Emanuel convection scheme produces a more realistic number of TCs than the

93 Grell scheme (Diro et al. 2014). Subsequently, Fuentes-Franco et al. (2017) showed that the 
94 Kain-Fritsch scheme was able to simulate observed TC activity better than the Emanuel scheme

95 over the same domain. Shen et al. (2019) also showed that the Kain-Fritsch scheme outperforms

96 other CPS in WRF simulations conducted over the CORDEX - East Asia domain, primarily

97 because of the better representation of large-scale environmental factors important to TC 98 activity.

99 Given the known importance of the choice of CPS to TCs in RCM simulations, the present 100 study aims to investigate the sensitivity of TCs to CPS found in the Regional Climate Model 101 Version 4 (RegCM4) focusing on the Philippine domain. Identifying the most appropriate CPS 102 will better inform which scheme to use when performing TC modeling studies for the country.

103 The paper is organized as follows. In Section 2, the datasets and RCM used in this study, as well 104 the CPS used in the simulations are described. Then, in Section 3, the simulated climatological 105 TC characteristics are compared with observations in terms of frequency, seasonality, track, 106 intensity, and associated rainfall. The large-scale environmental factors that could explain the 107 simulation of each CPS are discussed in Section 4. Finally, the key findings and conclusions are 108 summarized in Section 5.

\section{Data and methods}

\section{$110 \quad 2.1$ Model description and design of the experiments}

111 The present study utilizes the RegCM4, which is a hydrostatic, compressible, sigma112 pressure vertical coordinate-based RCM for long-term regional climate simulations (Giorgi et al. 113 2012). Specifically, the RegCM-4.4.5.5 version of the model is used, which has already been 114 used in recent studies to provide climate change projections for the Philippines (i.e., Gallo et al. 115 2019; Villafuerte et al. 2020). The model is run at a horizontal resolution of $25 \mathrm{~km}$ covering the 116 area bounded by the region $\left(0^{\circ}-30^{\circ} \mathrm{N}, 110^{\circ}-160^{\circ} \mathrm{E}\right.$; Fig. 1$)$. This domain was chosen to include a 
117 larger portion of the WNP, where TCs entering the PAR are most likely to originate (Gallo et al. 118 2019).

119 Five RegCM4 model simulations were conducted using the initial and lateral boundary 120 conditions taken from the ERA-Interim reanalysis (hereafter referred as ERAI; Berrisford et al. 121 2011) covering the period from 00UTC 01 December 1980 to 18 UTC 31 December 2010, and 122 employing several different CPS. The analysis of the model simulations covers a 30-year period 123 from 00UTC 01 January 1981 to 18 UTC 31 December 2010 to allow a one-month model spin124 up. The same model options for the other parameterization schemes, including the planetary 125 boundary layer (PBL), land surface, and radiative transfer were utilized in all simulations, i.e. 126 Holtslag PBL (Holtslag et al. 1990), CLM4.5 land surface model, explicit moisture scheme 127 (SUBEX) (Pal et al. 2000), Zeng ocean flux scheme (Zeng et al. 1998), and CCM3 radiative 128 transfer.

129 Among the CPS applied in this study are the Emanuel (Emanuel 1991), Grell with Arakawa130 Schubert closure (Grell 1993), Kain-Fritsch (Kain and Fritsch 1990), and Tiedtke (Tiedtke 131 1996). The Emanuel (EM) scheme triggers when the level of buoyancy exceeds the cloud base 132 level. Cloud mixing is episodic, inhomogeneous, and convective fluxes are based on a model of 133 sub-cloud-scale updrafts and downdrafts (Emanuel and Zivkovic-Rothman, 1999). The Grell 134 (GR) scheme considers the point where the lifting parcel reaches the moist convection level as 135 the triggering point for convection. An updraft and a penetrative downdraft compose the two 136 steady-state circulations that makes up the clouds (Grell 1993). The GR scheme in RegCM4 has 137 two closure types: (1) Arakawa-Schubert (AS) (Arakawa and Schubert 1974) and (2) Fritsch138 Chappell (FC) (Fritsch and Chappell 1980). In this study, the GR simulation uses the AS closure 139 wherein buoyant energy is released immediately at each time step. The Kain-Fritsch (KF) 
140 scheme uses a one-dimensional entraining and detraining plume model where negatively buoyant

141 parcels are assumed to detrain from the clouds, while positively buoyant parcels tend to entrain

142 into the clouds. This allows the model to modulate the mean thermodynamic characteristics

143 between convective clouds and the environment (Kain and Fritsch, 1990). The Tiedtke (TE)

144 scheme triggers convection when moisture convergence becomes greater than the boundary layer

145 moisture flux (Tiedtke 1989). The estimation of precipitation depends on the CPS over land or

146 ocean. For example, over tropical oceans, GR underestimates precipitation while EM

147 overestimates it for very intense events (Giorgi et al. 2012). To minimize such biases, the

148 RegCM4's ability to mix two schemes was considered in this study, i.e. GR scheme over land

149 and EM scheme over the ocean (GR-EM) (Giorgi et al. 2012). A brief description of the

150 RegCM4 simulations conducted in this study and their distinguishing features are summarized in 151 Table 1.

$152 \quad 2.2$ TC detection and observed dataset

153 The TC detection algorithm employed in this study follows the method used in Gallo et al. 154 (2019), which has also been used in a number of studies that have investigated TC climatologies 155 from RCM simulations (e.g., Manganello et al. 2012; Redmond et al. 2015; Liang et al. 2017; 156 Wang et al. 2017). Specifically, the TRACK software developed by Hodges (1995), which was 157 later improved to widen its applicability (i.e., Hodges 1996, 1999; Bengtsson et al. 2007), is used 158 to identify and track TC-like vortices (TCLVs) from the 6-hourly model outputs. The TC 159 detection and tracking algorithm involves six stages:

160 1. The vorticity fields at different pressure levels (850-, 500-, 300-, and 200-hPa) of the 161 troposphere are calculated. 
2. The $850-\mathrm{hPa}$ relative vorticity is then filtered to a spectral resolution of $\mathrm{T} 42$, on the original grid, to reduce noise resulting in more reliable tracking. All levels are also filtered to a T63 resolution to be used in the TCLV identification.

3. The tracking is performed by first identifying the vorticity maxima $>5.0 \times 10^{-6} \mathrm{~s}^{-1}$. These are then initialized into tracks using a nearest neighbor method and then refined by minimizing a cost function for track smoothness subject to adaptive constraints. All systems are initially tracked.

4. The vorticity maxima in the T63 filtered fields are iteratively added to the tracks within a $5^{\circ}$ radius in order to identify the TCLV. identification criteria are applied only over the ocean, exclude systems that do not have a warm core, and do not cover the whole troposphere. This stage ensures adherence to a warm core and a coherent vertical structure for the TCLV.

5. An initial identification is performed by applying criteria to all tracks that last longer than two days. Following Gallo et al. (2019) and Bengtsson et al. (2007), the

6. Finally, the maximum sustained wind speeds (MWS) is identified in the vicinity of the vortices. Detected storms that do not reach $17 \mathrm{~m} \mathrm{~s}^{-1}$ in their entire lifecycle are eliminated, following the same limit for the tropical storm (TS) category used in the JMA TC intensity scale.

Similar thresholds enumerated above are employed in identifying TCLVs for the ERAI and 182 dependent TC detection and tracking (e.g., Walsh et al. 2007) is not used in this study to see how 183 downscaling improves the representation of TCs. It also allows a direct comparison of TC- 
associated rainfall, which is defined as the rainfall within the $500 \mathrm{~km}$ radial distance from the 6hourly positions of the TC center following Zhang et al. (2019).

The spatial and temporal characteristics of simulated TCs are compared to the TC "best

187 track" data from the Japan Meteorological Agency (JMA), which is the designated body of the 188 World Meteorological Organization (WMO) as the Regional Specialized Meteorological Center 189 (RSMC) to cover TC forecasts and analysis over the WNP $\left(0^{\circ}-60^{\circ} \mathrm{N}, 100^{\circ}-180^{\circ} \mathrm{E}\right)$. Six-hourly 190 information of the TC MWS and locations are derived using the Dvorak technique (JMA 2018), 191 which uses visible and infrared images from geostationary and polar-orbiting weather satellites 192 (Barcikowska et al. 2012). The Dvorak current intensity (CI) number (Dvorak, 1975) is 193 converted to its equivalent 10-minute MWS using the Koba conversion table (Koba et al. 1989). 194 Although different methods are used for both the JMA observations and the model simulations in 195 showing TC activity, Barcikowska et al. (2012) determined that the JMA best track dataset 196 provides more reliable CI parameters than other datasets found in the WNP. Thus, it is the most 197 appropriate dataset for studies investigating the TC climatology.

198 The identified TC MWS are then classified according to the current TC categories 199 operationally being used by the Philippine Atmospheric, Geophysical and Astronomical Services 200 Administration (PAGASA) namely, 1) tropical depression (TD): MWS $<17 \mathrm{~m} \mathrm{~s}^{-1}$; 2) tropical 201 storm (TS): MWS ranging from 17 to $25 \mathrm{~m} \mathrm{~s}^{-1}$; 3) severe tropical storm (STS): MWS ranging 202 from 26 to $33 \mathrm{~m} \mathrm{~s}^{-1}$; 4) typhoon (TY): MWS ranging from 34 to $61 \mathrm{~m} \mathrm{~s}^{-1}$; and 5) super typhoon 203 (STY): MWS > $61 \mathrm{~m} \mathrm{~s}^{-1}$. As the study focuses mainly on TCs affecting the Philippines, only 204 those TCs that developed, entered, and/or existed over the PAR (see, Fig. 1) were considered in 205 the analyses. The PAR is among the agreed areas of responsibility for providing storm warnings 206 and shipping forecasts back in the mid-1960s (WMO 1966). Since then, PAGASA has been 
207 using the PAR for monitoring TCs and in providing TC-related warnings to the public (e.g.,

208 Cinco et al. 2016).

2093 Results

$210 \quad 3.1$ TC frequency

211 The time series of annual number of TCs in the PAR based on the JMA observations, ERAI, 212 and the five RegCM4 experiments are compared in Fig. 2. The frequency of observed TCs over 213 the PAR varies interannually; there are years where TCs are more active (e.g., in 1986, 1993214 1994, and 2004), while at times, TCs occur less frequently (e.g., from 1997 to 2002; thick black 215 curve in Fig. 2). These year-to-year variations in the occurrence of TCs over the PAR are 216 captured to some extent by the ERAI (gray curve) and the RegCM4 experiments, although with 217 some notable discrepancies. For instance, the observations recorded the lowest TC count in 2002 218 (10 TCs), while all of the five experiments simulate higher number of TCs over the PAR in that 219 particular year relative to the other years. Such discrepancies in the year-to-year variations with 220 the RegCM4-simulated TCs and observations led to insignificant and low correlation coefficients $221(r<0.20, p>0.05)$. It is also noted that there is an insignificant correlation $(r=0.48, p>0.05)$

222 between the ERAI and the JMA's time series of annual TC frequency over the PAR.

223 The distributions of annual TC frequency derived from the observations, ERAI, and the 224 RegCM4 simulations are also shown at the right hand side of Fig. 2. Higher (lower) interannual 225 variations are noted in EM, GR-EM, and KF (ERAI, GR, and TE) than the observations. The EM 226 scheme simulates the closest 30-year average annual TC frequency in the PAR at 12.9 TCs per 227 year compared to the observed annual mean TCs of $16.8 \mathrm{TCs}$ per year. The KF scheme, on the 228 other hand, overestimates the climatological mean annual TC frequency at $22.5 \mathrm{TCs}$ per year, 229 while the GR and TE simulate an average of 1.4 and 1.2 TCs per year, respectively. In general, 
230 the models tend to underestimate the annual-mean TC frequency, except for the RegCM4 231 simulation with KF scheme. Similar results of overestimation for KF (Shen et al. 2019), 232 underestimation for EM (Fuentes-Franco et al. 2017), and non-detection of TCLVs for the GR 233 schemes (Diro et al. 2014) were reported using ERAI-driven RCM simulations applied in 234 different regions of the world. It is also worth noting that fewer TCs occurring over the PAR are 235 similarly detected from the raw ERAI data (Fig. 2). Among the RegCM4 experiments, the EM 236 scheme tends to reproduce the most realistic annual TC frequency in the PAR, consistent with 237 the findings of Diro et al. (2014) over the Central American region.

\section{$238 \quad 3.2$ TC spatial density}

239 The spatial density of TCs was obtained based on the 6-hourly TC center location following 240 the track of model-simulated and observed TCs that existed in the PAR during the period 19812412010 , and then binned in each of the $2^{\circ} \times 2^{\circ}$ grid boxes covering the entire domain (Fig. 3).

242 Based on observations (Fig. 3a), the main concentration of TC activity is found largely over the

243 Pacific (northeastern section of the PAR) extending over the northern section of the Philippines

244 and the South China Sea (SCS; locally known as the West Philippine Sea). The TC spatial

245 density derived from the ERAI closely resembles that of observations, although with 246 underestimated values over the areas north of $10^{\circ} \mathrm{N}$ and some overestimation over the regions 247 south of $7^{\circ} \mathrm{N}$ (Fig. 3b). For the RegCM4 simulations, the EM, GR-EM, and KF (Fig. 3c, e, and f, 248 respectively) capture the general pattern of observed maximum spatial track density location 249 over the northeastern section of the PAR, although shifted more to the north in the model 250 simulations. It is also noted that the KF overestimated the TC occurrence over much of the 251 domain (Fig. 3f). 
The TC track density based on the GR and TE simulations (Fig. 3d and g, respectively) are

253 mainly concentrated over the SCS and the northern section of the PAR; both of them fail to

254 capture the main TC activity east of the PAR over the Pacific Ocean. Among the five RegCM4

255 experiments, GR-EM shows the most similar spatial pattern of TC track density with the

256 observations, although with noted overestimation over lower latitudes and fewer land falling TCs

257 over the northern portion of the Philippines.

\section{$258 \quad 3.3$ TC-associated rainfall}

259 The TC-associated rainfall was obtained within the $500 \mathrm{~km}$ radial distance from the center

260 of the TCs. Based on ERAI, this rainfall amounts to an annual average ranging from $50 \mathrm{~mm}$ to

261 more than $300 \mathrm{~mm}$ (Fig. 4a). A southeast-northwest elongated area characterizes the spatial

262 distribution of TC-associated rainfall, following the general pattern of TC tracks. The maximum

263 TC-associated rainfall (exceeding $300 \mathrm{~mm}$, on the average) is located over the Philippine Sea; it

264 accounts to about $10-15 \%$ of the annual rainfall over the region (contours in Fig. 4a). As with

265 the ERAI, the spatial pattern of TC-associated rainfall follows the general pattern of TC tracks in

266 the RegCM4 simulations. Hence, the earlier noted discrepancies with the observed TC tracks

267 propagate to the TC-associated rainfall. The EM, GR-EM, and much more, the KF simulation,

268 overestimated the TC-associated rainfall over much of the domain, particularly over the areas

269 south of $10^{\circ} \mathrm{N}$ (Fig. 4b, d, and e, respectively). In contrast, the RegCM4 simulations using GR

270 and TE schemes underestimated the TC-associated rainfall over the entire domain (Fig. $4 \mathrm{c}$ and $\mathrm{f}$,

271 respectively); this is primarily because of the largely underestimated number of TCs as shown

272 earlier.

273 The percentage of TC-rain contribution in the RegCM4-simulation using EM is higher by 274 approximately 5-10\% than the ERAI over the large areas of the Pacific Ocean and the SCS 
275 (contours in Fig. 4b). The center of maximum TC-rain contribution over the ocean, northeast of

276 the Philippines, is also shifted more to the north in the EM simulation. The spatial pattern of TC-

277 rain contribution of the GR-EM experiment is almost similar to EM, although smaller in

278 magnitude (Fig. 4d). An overestimated TC-rain contribution (as much as $20 \%$ higher than the

279 ERAI) is noted for KF over the entire domain (Fig. 4f). Because few TCs are forming over the

280 Pacific Ocean and only a handful of TCs were detected in the GR and TE, the annual mean

281 contribution of TC-associated rainfall is severely underestimated for these simulations (Fig. 4c

282 and f, respectively); it did not reach 5\% anywhere in the domain. Among all RegCM4

283 simulations, the GR-EM best represents the spatial pattern and magnitude of TC-associated

284 rainfall over the domain.

\section{$285 \quad 3.4$ TC seasonality}

286 The monthly average number of TCs that existed in the PAR from 1981 to 2010 is shown in

287 Fig. 5. Based on observations (thick solid line in Fig. 5) TCs are less active in the PAR during

288 the months of January-April and gradually increases from May until it reaches the peak TC

289 activity in July-September. Then, the TC activity over the PAR decreases in the following

290 months from October until December. These main characteristics of the TC annual cycle are well

291 reproduced by the ERAI, although with consistently fewer number of TCs. On the other hand,

292 some of these key features are similarly reproduced in the five RegCM4 experiments. For

293 instance, the low TC activity over the PAR from January-April is generally reproduced by the

294 RegCM4 experiments, except for some overestimation in the KF, EM, and GR-EM simulations.

295 The RegCM4 simulations also captured the start of having more active TCs in May and June.

296 The TC peak season over the PAR that occurs during the months of July-September is

297 reproduced by the KF, EM, and GR-EM simulations, despite the overestimation in KF and 
underestimation in EM and GR-EM. All model experiments tend to underestimate TC activity

299 over the PAR in October. The observed TCs over the PAR in December are overestimated by the $300 \mathrm{KF}, \mathrm{EM}$, and GR-EM schemes. The pronounced seasonality of TC activity over the PAR, on the 301 other hand, is not observed in the GR and TE simulations.

The TC tracks aggregated for each quarter of the year: January-March (JFM), April-June (AMJ), July-September (JAS), and October-December (OND), are compared in Fig. 6. There are some noted discrepancies between the observed and model-simulated seasonal TC tracks covering the 30-year period (1981-2010). During the least active TC season of JFM (leftmost

306 column of Fig. 6), the observed TC tracks generally propagate in a westward direction making 307 landfall over the central portions of the Philippines. This westward propagation of the TCs are 308 somewhat captured by the EM, GR-EM, and KF RegCM4 simulations despite the fewer TCs in 309 the ERAI, but in greater number and with trajectories passing more to the southern region of the 310 Philippines. For the pre-TC season months of AMJ (second column from the left of Fig. 6), the 311 observations exhibit a re-curving pattern towards the northeast of the PAR. For the EM, GR-EM, 312 and KF experiments, the re-curving pattern tends to be shifted to the east by about 4-6 $6^{\circ}$ (Fig. $6 \mathrm{c}$, 313 e, and f, respectively). There are also more TC tracks in KF than observed over the SCS (Fig. 314 6f). Meanwhile, GR and TE fail to simulate much of the TCs that are generally formed south of $31515^{\circ} \mathrm{N}$ over the Pacific Ocean (Fig. $6 \mathrm{~d}$ and g, respectively). Among the RegCM4 experiments, 316 GR-EM best represents the TC tracks during JFM, while EM and GR-EM simulations best 317 capture the AMJ TC tracks.

318 The most active TC season of JAS illustrates that TCs generally affect the northern regions 319 of the Philippines (third column from the left of Fig. 6). Also, TCs tend to exit either to the north 320 or northwest of the PAR. Such TC trajectories are well captured by the ERAI and to some extent 
321 in the EM, GR-EM, and KF simulations, although KF indicates more westward moving tracks

322 (Fig. 6f). Similar to the AMJ season, GR and TE fail to simulate TCs in a large area east of the 323 PAR over the Pacific Ocean (Fig. 6d and g, respectively). During the OND season, the JMA best 324 track data indicates that most of the TCs move westward making landfall over the northern and 325 central Philippines, although some TCs tend to re-curve and move away from the country toward 326 higher latitudes (rightmost panel of Fig. 6a). Such pattern is well represented in the ERAI and to 327 some extent, in the EM, GR-EM, and KF experiments, although shifted more to lower latitudes 328 affecting the southern regions of the Philippines (rightmost panel of Fig. 6b, c, e, and f, 329 respectively). Furthermore, there appears to be more TCs originating south of $5^{\circ} \mathrm{N}$ in the model 330 simulations. As noted in the other seasons, relatively fewer (more) TCs were detected in the GR 331 and TE (KF) in OND. Among the five RegCM4 experiments used in this study, GR-EM best 332 represents the observed TC tracks for the JAS and OND seasons.

333 Figure 6 further reveals that stronger TCs generally occur during the latter half of the year. $334 \mathrm{KF}$ was able to capture stronger TCs occurring in JAS, but not in OND. Similar to the ERAI, all 335 RegCM4 experiments tend to simulate mainly the weaker TCs (i.e. TD and TS), underestimate 336 the number of STS and TY, and do not simulate any STY occurrences for any given season. The 337 GR and TE schemes were only able to simulate up to TS categories, which are mostly located at 338 higher latitudes approximately over $12^{\circ}-18^{\circ} \mathrm{N}$ and $15^{\circ}-25^{\circ} \mathrm{N}$, respectively; while EM and GR339 EM fail to capture numerous landfalling intense TCs. Among the five RegCM4 experiments 340 using different CPS, the KF scheme best captures the TC intensities in most of the seasons 341 analyzed. 


\subsection{TC intensity}

343 Figure 7 compares the kernel density plots obtained from the TC lifetime highest MWS of 344 observation, reanalysis, and the RegCM4 simulations. Figure 7 shows the broad range covered 345 by the distribution of the highest MWS of the TCs observed in the PAR from 1981 to 2010 (thick 346 black curve in Fig. 7). Most of the observed TCs obtain their lifetime highest MWS in the range 347 from 20 to $50 \mathrm{~m} \mathrm{~s}^{-1}$, with a few reaching $>60 \mathrm{~m} \mathrm{~s}^{-1}$. In contrast, the ERAI and RegCM4 348 simulations produce distributions that are skewed towards weak to moderate wind speed values, 349 and fail to simulate TCs with the strongest intensities (i.e. no TC intensity above $50 \mathrm{~m} \mathrm{~s}^{-1}$ ). Such

350 results were similarly found by Shen et al. (2019) for the simulated TCs conducted over the 351 CORDEX-East Asia region, attributing the weaker TCs to coarse resolution model simulations.

352 Figure 7 further reveals that stronger TCs were achieved in the downscaled RegCM4 353 experiments (i.e., EM, GR-EM, and KF) when compared to the ERAI, signifying the added value 354 of downscaling as noted in a number of studies (e.g., Diro et al. 2014; Jin et al. 2016; Fuentes355 Franco et al. 2017). It also stresses the crucial role of CPS in simulating TC intensities. Despite 356 the higher resolution in GR and TE simulations relative to the ERAI, they tend to produce TCs 357 with weaker intensities. The EM and the combined GR-EM schemes have an almost similar 358 distribution of lifetime highest 6-hourly MWS for all TCLVs that existed in the PAR. Among the 359 RegCM4 simulations conducted in this study, the KF scheme was able to simulate stronger TCs. 360 These results further support the findings of Fuentes-Franco et al. (2017) and Shen et al. (2019) 361 even if applied in different regions of the world.

\section{$362 \quad 3.6$ TC lifespan}

363 The lifespan of each of the TCs that existed in the PAR from 1981 to 2010 is summarized in 364 Fig. 8. On average, the TCs last for about $150 \mathrm{~h}$ over the entire domain for the observations 
(marked by the horizontal line inside the box in Fig. 8a). The ERAI and RegCM4 simulated TCs, 366 on the other hand, tend to have longer lifecycles, and wider variations among the individual TCs

367 as characterized by the higher interquartile range (the area covered by the boxes in Fig. 8a). This

368 extended TC lifecycle for all experiments and the reanalysis is associated with the densely

369 extended TC tracks over the eastern part of the domain over the Pacific Ocean and more

370 westward tracks of the TCs for the majority of the seasons (as shown in Fig. 6). TCs with such

371 characteristics typically have longer lifespans because they stay at lower latitudes longer (Shen et

372 al. 2019). These longer lifecycles obtained from the model-simulated TCs as compared to the

373 best track data can also be attributed to the uncertainty in observations of weak storms (e.g.,

374 Hodges et al. 2017).

375 Inside the PAR, TCs are observed to stay for about $90 \mathrm{~h}$ on average based on the JMA 376 observations (horizontal line inside the black box in Fig. 8b). Again, ERAI and all RegCM4

377 experiments overestimate the TC duration inside the PAR (Fig. 8b), which can be due to the 378 tendency of the simulated TCs for a westward track instead of re-curving to the northwest 379 direction (see, Fig. 6). Among all experiments, the RegCM4 experiment using GR-EM scheme 380 best simulates the TC life span over the PAR.

\section{Discussion}

382 To further investigate the biases obtained by the RegCM4 experiments conducted in this 383 study on TC activity over the PAR, the large-scale conditions governing the formation and 384 development of TCs are discussed in this section. Past studies have pointed out that TC 385 formation and their subsequent movements are greatly influenced by how the large-scale 386 circulation is simulated by the model (e.g. Au-Yeung and Chan 2012; Jin et al. 2016; Liang et al. 
2017; Shen et al. 2019). Here, we focus on analyzing the most active TC season (JAS) over the

PAR.

Over the WNP, TC formation and subsequent development occur under favorable conditions such as positive values of 850 -hPa relative vorticity and weak vertical wind shear (Jin et al. 2016). The RegCM4-simulated climatological mean 850 -hPa relative vorticity and vertical wind 392 shear (i.e., the difference in the zonal winds between the $850 \mathrm{hPa}$ and $200 \mathrm{hPa}$ levels) are 393 compared with the ERAI (Fig. 9). The 850-hPa relative vorticity in the ERAI is characterized by 394 a northwest-southeast elongated positive belt extending from the SCS to the WNP between $5^{\circ}-$ $39523^{\circ} \mathrm{N}$, with the maximum center over the SCS. The positive belt of the relative vorticity is associated with the monsoon trough, a vital factor for TC genesis in the region (Holland 1995;

397 Wu 2012). The northwest-southeast orientation of the positive vorticity belt is likewise obtained 398 by the RegCM4 experiments, although the belt is disconnected at different parts over the domain.

399 For both the EM and GR-EM experiments, the positive vorticity zone located northwest of the 400 Philippines over the SCS is disconnected (Fig. 9b and d, respectively). The KF experiment, on 401 the other hand, shows a more extended positive vorticity belt to the northeast of the Philippines 402 (Fig. 9e). The location of positive vorticity zone east of the Philippine landmass up to $140^{\circ} \mathrm{E}$ is 403 slightly shifted to the north for the three CPS experiments (EM, GR-EM, and KF), which leads 404 to the location of TC formation more to the north thereby having more TCs passing north of the 405 domain, freeing much of the central portion of the Philippines (see, Fig. 6). A wide area of 406 positive vorticity located east of the Philippines is absent in both the GR and TE experiments 407 (Fig. 9c and f, respectively). This in turn, inhibits the formation of TCs over the Pacific Ocean 408 resulting in a large underestimation of TCs in these experiments. The simulated vertical wind 409 shear of all CPS experiments generally captures the observed spatial pattern, wherein low values 
410 of vertical wind shear dominates over the regions east of $140^{\circ} \mathrm{E}$ and north of $15^{\circ} \mathrm{N}$ of the entire

411 domain. According to Gray (1979), vertical wind shear values of less than $10 \mathrm{~m} \mathrm{~s}^{-1}$ are favorable

412 for TC formation and development. Since the locations of areas with favorable vertical wind

413 shear that are simulated by all CPS experiments are generally similar, this implies that the

414 vertical wind shear is not a dominant environmental factor that affects the TCs in the RegCM4

415 simulations conducted in this study.

416 In addition to the earlier mentioned large-scale environmental factors, the RegCM4-

417 simulated climatological mean $850-\mathrm{hPa}$ winds, 500-hPa geopotential heights, and 700-hPa

418 relative humidity are compared with the ERAI in JAS season (Fig. 10). All RegCM4

419 experiments are able to capture the low-level southwesterly wind flow associated with the

420 prevailing summer monsoon season in JAS albeit with noted stronger (weaker) southwesterly

421 flows in the KF (GR and TE) experiment(s). Such stronger southwesterly low-level wind flow in

422 the KF experiment, relative to the ERAI, can be attributed to the weak and eastward-shifted

423 WNP subtropical high pressure system; thereby more moisture is transported farther to the east

424 and northeast of the Philippines (Fig. 10e).

425 Drier mid-tropospheric conditions (represented by the $700-\mathrm{hPa}$ relative humidity, shadings

426 in Fig. 10) are observed for the GR and TE experiments over large areas of the domain,

427 particularly over the Pacific Ocean south of $15^{\circ} \mathrm{N}$, where most TCs entering the PAR are

428 generated (Fig. 10c and f, respectively). Similar dry bias in GR has been noted in Im et al. (2008)

429 attributing it to the infrequent triggering of the scheme. The dry bias in TE, on the other hand, is

430 attributed by Ali et al. (2015) to the underestimated surface latent heat flux and more stable

431 structure of the atmosphere from the surface up to the mid-tropospheric level. According to Gray

432 (1979), dry mid-tropospheric conditions are unfavorable for TC formation due to the entrainment 
433 of dry air causing air parcels to lose buoyancy and inhibit deep convection (Cheung 2004). The

434 relatively drier mid-tropospheric environment in the GR and TE experiments (in comparison to

435 the other CPS and with the ERA-Interim reanalysis) serves as one of the main reasons why there

436 are no TCs forming south of $15^{\circ} \mathrm{N}$ over the Pacific Ocean in these experiments (see, Fig. 6). In

437 an earlier climate modeling study, Strachan et al. (2013) identified the mid-tropospheric relative

438 humidity as the dominant factor to affect TC activity over the WNP.

439 The western edge of the WNP subtropical high [represented by the 5880-geopotential meter

440 (gpm) contour line; e.g., Kim et al. (2015)] is known to be the main steering flow that influences

441 the track of TCs over the WNP (Ho et al. 2004). Based on the ERAI, the 5880-gpm contour line

442 extends east of Taiwan over the Pacific Ocean during JAS (Fig. 10a). However, all CPS

443 experiments underestimate the 500-hPa geopotential height by about $20-30 \mathrm{~m}$ indicating a

444 weaker WNP subtropical high in the RegCM4 simulations (Fig. 10b-f). Such a condition favors

445 the TCs that are formed southeast of the Philippines over the Pacific Ocean to re-curve over the

446 ocean and move toward Japan and Korea (Kim et al. 2015). This explains the eastward shift of

447 the TC tracks and the earlier re-curvature taken by the TCs in the RegCM4 experiments as noted

448 in Section 3.4.

\section{Conclusions}

450 This study has investigated the sensitivity of simulated TCs affecting the Philippines to the 451 different CPS in RegCM4. Five ERAI-driven RegCM4 simulations using different CPS were 452 conducted covering a 30-year period of investigation (i.e., 1981-2010). A TC detection 453 algorithm that looks at the dynamic and thermodynamic characteristics of a system from the 6454 hourly output of the model was used to identify the TCs. Results show that the chosen CPS 455 affects different TC characteristics, including the frequency, seasonality, intensity, track, 
456 associated rainfall, and lifecycles of the model-simulated TCs over the PAR. Among the five

457 CPS used in the RegCM4 simulations, the EM scheme yielded an annual-mean TC frequency

458 over the PAR that is closest to observations. The combined GR-EM schemes closely reproduced

459 the spatial pattern of the TC track density covering the entire period, the TC-associated rainfall,

460 the seasonal patterns of TC tracks, and the TC lifespan over the PAR. The KF scheme, on the

461 other hand, is the only CPS that was able to simulate stronger TCs within the domain. However,

462 there are some noted discrepancies with the observed and simulated TCs. For instance, the

463 models have some difficulty in capturing the annual frequency of TCs over the PAR; none of

464 them obtained a significant correlation with the observed values. The timing of the pronounced

465 seasonality of TC occurrence over the PAR is also not well captured in the RegCM4

466 experiments. Furthermore, the TC tracks are slightly displaced in the model simulations.

467 The biases obtained from the RegCM4 simulations using different CPS can be explained by

468 how realistic the large-scale environmental conditions governing TC formation and subsequent

469 movement are simulated by the model. The pattern of earlier TC re-curvature is due to the

470 weaker WNP subtropical high, while the northward shift of the simulated positive low-level

471 vorticity belt for EM, GR-EM, and much more with the KF, results in the TC genesis being more

472 to the north thereby having more TCs passing north of the domain, deviating away from the

473 central portion of the Philippines (see, Section 3.4). Shen et al. (2019) have similarly noted an

474 overestimation and northward shift of the TC track density over the CORDEX-East Asia domain

475 with the KF scheme, despite using a different RCM, attributing such bias to the extended

476 Intertropical Convergence Zone and overestimated relative humidity over the WNP region. The

477 RegCM4 simulations with GR and TE schemes underestimate the 700-hPa relative humidity

478 over large areas of the domain, particularly east of the Philippines over the Pacific Ocean, which 
479 creates a dry environment where deep convection is restricted, thereby inhibiting TC formation

480 and further development. Such conditions lead to almost no TCs forming over the Pacific Ocean

481 for these experiments, agreeing with the earlier findings of Strachan et al. (2013), who showed

482 that the mid-tropospheric relative humidity is the dominant factor that affects TC activity over 483 the WNP.

484 The TC detection thresholds applied uniformly in this study for both the native ERAI 485 resolution and the downscaled RegCM4 simulations revealed that the higher resolution achieved 486 through downscaling could either improve or worsen the simulated TCs, which depend on the 487 chosen CPS (as shown in Sections 3 and 4). This is in agreement with the findings of Murakami 488 (2014), who showed that even for reanalysis the highest resolution does not always best 489 represent the properties of TCs, mainly because the simulated TCs are highly dependent on the 490 model formulation (Schenkel and Hart 2012). The current findings stress the importance of 491 choosing the appropriate CPS for TC climate simulations given its impacts on various TC 492 characteristics as similarly noted in earlier studies (e.g., Prater and Evans 2002; Yoshimura et al. 493 2006; Kanada et al. 2012; Pattanayak et al. 2012; Sun et al. 2015). It has to be noted, however, 494 that the chosen CPS may interact differently with the other parameterized physical processes in 495 the model (e.g., Cruz and Narisma 2016; Fuentes-Franco et al. 2017), which may eventually 496 affect the simulated TCs. Nonetheless, the results obtained in the present study has increased the 497 confidence of the derived projected future changes in TCs over the Philippines, i.e. the GR-EM 498 scheme was used in the RegCM4 simulations in Gallo et al. (2019). The results reported here can 499 also be used (e.g., in selecting the appropriate CPS, investigating the added value of 500 downscaling, or further model tuning) for TC-related modeling studies in the future. 


\section{Acknowledgments}

503 We thank the Abdus Salam International Centre for Theoretical Physics (ICTP) and the regional 504 climate modeling community for providing the RegCM4 and the necessary files needed to run 505 the model. We appreciate the funding support provided by the Department of Science and 506 Technology - Philippine Council for Industry, Energy, and Emerging Technology Research 507 Development (DOST-PCIEERD) under project number 2018-03691, which made this study 508 possible. We are also thankful to Ms. Jennifer Tibay of the Manila Observatory and the rest of 509 the members of the CORDEX-Southeast Asia Philippines team for their comments and 510 suggestions in the earlier version of the manuscript. The computing facility of PAGASA has

511 allowed the model simulations conducted in this study. The insights and recommended revisions 512 provided by the anonymous reviewers are gratefully acknowledged.

\section{References}

515 Ali S, Li D, Congbin F, Yang Y (2015) Performance of convective parameterization schemes in 516 Asia using RegCM: simulations in three typical regions for the period 1998-2002. Advances 517 in Atmospheric Sciences 32:715-730.

518 Arakawa A, Schubert WH (1974) Interaction of a cumulus cloud ensemble with the large scale 519 environment. J Atmos Sci 31:674-701. https://doi.org/10.1175/15200469(1974)031<0674:IOACCE>2.0.CO;2

521 Au-Yeung AYM, Chan JCL (2012) Potential use of a regional climate model in seasonal tropical 522 cyclone activity predictions in the western North Pacific. Clim Dyn 39:783-794. 523 https://doi.org/10.1007/s00382-011-1268-x 
524 Bagtasa G (2017) Contribution of Tropical Cyclones to Rainfall in the Philippines. J Climate 30:

525 3621-3633. https://doi.org/10.1175/JCLI-D-16-0150.1

526 Barcikowska M, Feser F, Storch HV (2012) Usability of best track data in climate statistics in the 527 western north pacific. Mon Wea Rev 140:2818-2830. https://doi.org/10.1175/MWR-D-1100175.1

529 Bengtsson L, Hodges KI, Esch M, Keenlyside N, Kornblueh L, Luo JJ, Yamagata T (2007) How 530 may tropical cyclones change in a warmer climate? Tellus A: Dynamic Meteorology and $531 \quad$ Oceanography. 59:4, 539-56.1 https://doi.org/10.1111/j.1600-0870.2007.00251.x

532 Berrisford P, Kalberg P, Kobayashi S, Dee D, Uppala S, Simmons AJ, Poli P, Sato H (2011) 533 Atmospheric conservation properties in ERA-Interim. Q J R Meteorol Soc 137: 1381-1399. $534 \quad$ https://doi.org/10.1002/qj.864

535 Biswas MK, Bernardet L, Dudhia J (2014) Sensitivity of hurricane forecasts to cumulus 536 parameterizations in the HWRF model. Geophys Res Lett 41: 9113-9119. $537 \quad$ https://doi.org/10.1002/2014GL062071.

538 Blanc E, Strobl E (2016) Assessing the impact of typhoons on rice production in the Philippines.

$539 \quad$ J Appl Meteor Clim 55: 993-1007. https://doi.org/10.1175/JAMC-D-15-0214.1

540 Cheung KKW (2004) Large-Scale Environmental Parameters Associated with Tropical Cyclone 541 Formations in the Western North Pacific. J Climate 17: 466-484. 542 https://doi.org/10.1175/1520-0442(2004)017<0466:LEPAWT>2.0.CO;2

543 Cinco TA, de Guzman RG, Ortiz AMD, Delfino RFP, Lasco RD, Hilario FD, Juanillo EL, Barba $544 \quad$ R Ares ED (2016) Observed trends and impacts of tropical cyclones in the Philippines. Int J 545 Climatol 36: 4638-4650. https://doi.org/10.1002/joc.4659 
546 Cruz FT, Narisma GT (2016) WRF simulation of the heavy rainfall over Metropolitan Manila,

547 Philippines during tropical cyclone Ketsana: a sensitivity study. Meteorol Atmos Phys $548 \quad$ 128:415-428. https://doi.org/10.1007/s00703-015-0425-X

549 Diro GT, Giorgi F, Fuentes-Franco R, Walsh KJE, Giuliani G, Coppola E (2014) Tropical 550 cyclones in a regional climate change projection with RegCM4 over the CORDEX Central $551 \quad$ America domain. Clim Change 125: 79-94. https://doi.org/10.1007/s10584-014-1155-7

552 Dvorak VF (1975) Tropical cyclone intensity analysis and forecasting from satellite visible or 553 enhanced infrared imagery. Mon Wea Rev 103: 420-430. https://doi.org/10.1175/1520$554 \quad$ 0493(1975) $103<0420:$ TCIAAF $>2.0 . \mathrm{CO} ; 2$

555 Emanuel KA (1991) A scheme for representing cumulus convection in large-scale models. J

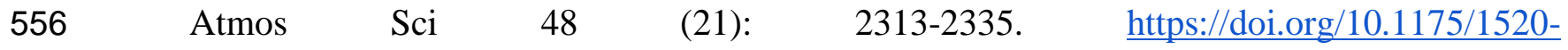
$557 \quad \underline{0469(1991) 048}<2313: A S F R C C>\underline{2.0 . C O} ; 2$

558 Emanuel KA, Zivkovic-Rothman M (1999) Development and evaluation of a convection scheme 559 for use in climate models. J Atmos Sci 56: 1766-1782. https://doi.org/10.1175/1520560 0469(1999)056<1766:DAEOAC>2.0.CO;2

561 Fritsch JM, Chappell CF (1980) Numerical prediction of convectively driven mesoscale pressure 562 systems Part II Mesoscale model. J Atmos Sci 37: 1734-1762. https://doi.org/10.1175/1520$563 \quad 0469(1980) 037<1722: \mathrm{NPOCDM}>2.0 . \mathrm{CO} ; 2$

564 Fuentes-Franco R, Giorgi F, Coppola E, Zimmermann K (2017) Sensitivity of tropical cyclones 565 to resolution, convection scheme and ocean flux parameterization over Eastern Tropical 566 Pacific and Tropical North Atlantic Oceans in the RegCM4 model. Clim Dyn 49: 547-561. $567 \quad$ https://doi.org/10.1007/s00382-016-3357-3 
568 Gallo F, Daron J, Macadam I, Cinco T, Villafuerte M, Buonomo E, Tucker S, Hein-Griggs D, 569 Jones RG (2019) High-resolution regional climate model projections of future tropical 570 cyclone activity in the Philippines. Int J Climatol 39: 1181-1194. $571 \quad$ https://doi.org/10.1002/joc.5870

572 Giorgi F, Coppola E, Solmon F, Mariotti L, Sylla MB, Bi X, Elguindi N, Diro DT, Nair V, 573 Giuliani G, Turuncoglu UU, Cozzini S, Guttler L, O’Brien TA, Tawfik AB, Shalaby A, 574 Zakey AS, Steiner AL, Stordal F, Sloan LC, Brankovic C (2012) RegCM4: Model 575 description and preliminary tests over multiple CORDEX domains. Clim Res 52: 7-29. $576 \quad$ https://doi.org/10.3354/cr01018

577 Giorgi F, Gutowski WJJ (2015) Regional Dynamical Downscaling and the CORDEX Initiative. 578 Annu Rev Environ Resour 40:467-490. https://doi.org/10.1146/annurev-environ-102014$579 \quad 021217$

580 Gray WM (1979) Hurricanes: Their formation, structure and likely role in the tropical 581 circulation. Meteorology over the Tropical Oceans. D. B. Shaw, Ed., Royal Meteorological $582 \quad$ Society $155-218$

583 Grell GA (1993) Prognostic evaluation of assumptions used by cumulus parameterizations. Mon 584 Wea Rev 121: 764-787

586 Gupta S (2010) Synthesis report on Ten ASEAN countries disaster risks assessment: ASEAN 587 Disaster Risk Management Initiative https://doi.org/10.13140/RG.2.2.32014.36160

588 Haarsma RJ, Roberts MJ, Vidale PL, Senior CA, Bellucci A, Bao Q, Chang P, Corti S, Fuckar 589 NS, Guemas V, von Hardenberg J, Hazeleger W, Kodama C, Koenigk T, Leung LR, Lu J, 590 Luo J-J, Mao J, Mizielinski MS, Mizuta R, Nobre P, Satoh M, Scoccimarro E, Semmler T, 
Small J, von Storch J-S (2016) High Resolution Model Intercomparison Project (HighResMIP v1.0) for CMIP6. Geosci Model Dev 9:4185-4208. https://doi.org/10.5194/gmd-9-4185-2016

594 Ho C-H, Baik J-J, Kim J-H, Gong D-Y, Sui C-H (2004) Interdecadal changes in summertime 595 typhoon tracks. J Climate 17: 1767-1776. https://doi.org/10.1175/1520$596 \quad \underline{0442(2004) 017<1767: \text { ICISTT }>2.0 . C O ; 2}$

597 Hodges KI (1995) Feature tracking on the unit sphere. Mon Wea Rev 123: 3458-3465. $598 \quad$ https://doi.org/10.1175/1520-0493(1995)123<3458:FTOTUS>2.0.CO;2

599 Hodges KI (1996) Spherical nonparametric estimators applied to the UGAMP model integration 600 for AMIP. Mon Wea Rev 124: 2914-2932. https://doi.org/10.1175/1520$601 \quad$ 0493(1996)124<2914:SNEATT>2.0.CO;2

602 Hodges KI (1999) Adaptive constraints for feature tracking. Mon Wea Rev 127: 1362-1373. 603 https://doi.org/10.1175/1520-0493(1999)127<1362:ACFFT>2.0.CO;2

604 Hodges KI, Cobb A, Vidale PL (2017) How Well Are Tropical Cyclones Represented in 605 Reanalysis Datasets? J Climate 30:5243-5264

606 Holland GJ (1995) Scale interaction in the Western Pacific Monsoon. Meteorl Atmos Phys 607 56:57-79. https://doi.org/10.1007/BF01022521

608 Holtslag A, de Bruijn E, Pan HL (1990) A high resolution air mass transformation model for 609 short-range weather forecasting. Mon Weather Rev 118: 1561-1575. 610 https://doi.org/10.1175/1520-0493(1990)118<1561:AHRAMT>2.0.CO;2

611 Im E-S, Ahn J-B, Remedio AR, Kwon W-T (2008) Sensitivity of the regional climate of 612 East/Southeast Asia to convective parameterizations in the RegCM3 modelling system. Part 613 1: focus on the Korean Peninsula. Int. J. Climatol. 28: 1861-1877. 
614 JMA (2018) Annual report on the activities of the RSMC Tokyo - Typhoon Center 2017

615 Jin CS, Cha DH, Lee DK, Suh MS, Hong SY, Kang HS, Ho CH (2016) Evaluation of

616 climatological tropical cyclone activity over the western North Pacific in the CORDEX-East

617 Asia multi-RCM simulations. Clim. Dyn 47: 765-778. https://doi.org/10.1007/s00382-015-

$618 \quad 2869-6$

619 Kain JS, Fritsch JM (1990) A one-dimensional entraining/detraining plume model and its 620 application in convective parameterization. J Atmos Sci 47: 2784-2802. 621 https://doi.org/10.1175/1520-0469(1990)047<2784:AODEPM>2.0.CO;2

622 Kanada S, Wada A, Nakano M, Kato T (2012) Effect of planetary boundary layer schemes on 623 the development of intense tropical cyclones using a cloud-resolving model. J Geophys Res 624 117: D03107. https://doi.org/10.1029/2011JD016582,2012

625 Kim D, Jin CS, Ho CH, Kim J, Kim JH (2015) Climatological features of WRF-simulated 626 tropical cyclones over the western North Pacific. Clim Dyn 44: 3223-3235. https://doi.org/10.1007/s00382-014-2410-3

628 Knutson TR, Tuleya RE (2004) Impact of $\mathrm{CO}_{2}$-induced warming on simulated hurricane 629 intensity and precipitation: Sensitivity to the choice of climate model and convective 630 parameterization. J Climate 17:3477-3495. https://doi.org/10.1175/1520$631 \quad 0442(2004) 017<3477:$ IOCWOS $>2.0 . \mathrm{CO} ; 2$

632 Koba H, Osano S, Hagiwara T, Akashi S, Kikuchi T (1989) Determination of intensity of 633 typhoons passing through the Philippine Islands (in Japanese). J Meteor Res 41:157-162

634 Lansigan FP, de los Santos WL, Coladilla JO (2000) Agronomic impacts of climate variability 635 on rice production in the Philippines, Agriculture. Ecosystems and Environment 82: 129636 137. https://doi.org/10.1016/S0167-8809(00)00222-X 
637 Liang J, Wang C, Hodges K (2017) Evaluation of tropical cyclones over the South China Sea

638 simulated by the $12 \mathrm{~km}$ MetUM regional climate model. Q J R Meteorol Soc 143: 1641639 1656. https://doi.org/10.1002/qj.3035

640 Manganello JV, Hodges KI, Kinter JL, Cash BA, Marx L, Jung T, Achuthavarier D, Adam JM, 641 Altshuler EL, Huang B (2012) Tropical Cyclone Climatology in a 10-km Global 642 Atmospheric GCM: Toward Weather-Resolving Climate Modeling. J Clim 25:3867-3893. 643 https://doi.org/10.1175/JCLI-D-11-00346.1.

644 Mohandas S, Ashrit R (2014) Sensitivity of different convective parameterization schemes on 645 tropical cyclone prediction using a mesoscale model. Nat Hazards 73:213-235. 646 https://doi.org/10.1007/s11069-013-0824-6

647 Murakami H (2014) Tropical cyclones in reanalysis data sets. Geophys Res Lett 41:2133-2141.

648 Pal JS, Small E, Eltahir E (2000) Simulation of regional-scale water and energy budgets: 649 representation of subgrid cloud and precipitation processes within RegCM. J Geophys Res $650 \quad$ 105: 29579-29594. https://doi.org/10.3354/cr01082

651 Pattanayak S, Mohanty UC, Osuri KK (2012) Impact of parameterization of physical processes 652 on simulation of track and intensity of tropical cyclone Nargis (2008) with WRF-NMM 653 Model. The Scientific World Journal 2012: 1-18. https://doi.org/10.1100/2012/671437

654 Prater BE, Evans JL (2002) Sensitivity of modeled tropical cyclone track and structure of 655 hurricane Irene (1999) to the convective parameterization scheme. Meteorol Atmos Phys 80: $656 \quad 103-115$. https://doi.org/10.1007/s007030200018

657 Rao DVB, Prasad DH (2007) Sensitivity of tropical cyclone intensification to boundary layer and 658 convective processes. Nat Hazards 41:429-445. https://doi.org/10.1007/s11069-006-9052-7 
659 Redmond G, Hodges KI, McSweeney C, Jones R, Hein D (2015) Projected changes in tropical 660 cyclones over Vietnam and the South China Sea using a $25 \mathrm{~km}$ regional climate model 661 perturbed physics ensemble. Clim Dyn 45:1983-2000. https://doi.org/10.1007/s00382-014$662 \quad 2450-8$

663 Schenkel BA, Hart RE (2012) An examination of tropical cyclone position, intensity, and 664 intensity lifecycle within atmospheric reanalysis datasets. J Climate 25: 3453-3475

665 Shen W, Song J, Liu G, Zhuang Y, Wang Y, Tang J (2019) The effect of convection scheme on 666 tropical cyclones simulations over the CORDEX East Asia domain. Clim Dyn 52: 4695667 4713. https://doi.org/10.1007/s00382-018-4405-y

668 Strachan J, Vidale PL, Hodges K, Roberts M, Demory ME (2013) Investigating global tropical 669 cyclone activity with a hierarchy of AGCMs: the role of model resolution. J Climate 26: 133-152. https://doi.org/10.1175/JCLI-D-12-00012.1

671 Sugi M, Murakami H, Yoshimura J (2009) A reduction in global tropical cyclone frequency due 672 to global warming. SOLA 5:164-167. https://doi.org/10.2151/sola.2009-042

673 Sun Y, Zhong Z, Lu W, Hu Y (2015) Why are tropical cyclone tracks over the western north 674 pacific sensitive to the cumulus parameterization scheme in regional climate modeling? A 675 case study for Megi (2010). Mon Wea Rev 142:1240-1249. https://doi.org/10.1175/MWR$676 \quad \underline{D}-13-00232.1$

677 Tang B, Camargo SJ (2014) Environmental control of tropical cyclones in CMIP5: A ventilation 678 perspective. JAMES 6:115-128. https://doi.org/10.1002/2013MS000294

679 Tiedtke M (1989) A comprehensive mass flux scheme for cumulus parameterization in large680 scale models. Mon Wea Rev 117: 1779-1800. https://doi.org/10.1175/1520$681 \quad$ 0493(1989)117<1779:ACMFSF $>2.0 . C O ; 2$ 
682 Tiedtke M (1996) An extension of cloud-radiation parameterization in the ECMWF model: the 683 representation of subgrid-scale variations of optical depth. Mon Wea Rev 124:745-750. 684 https://doi.org/10.1175/1520-0493(1996)124<0745:AEOCRP>2.0.CO;2

685 Villafuerte MQ, Macadam I, Daron J, Katzfey J, Cinco TA, Ares ED, Jones RG (2020) Projected 686 changes in rainfall and temperature over the Philippines from multiple dynamical 687 downscaling models. Int J Climatol 40:1784-1804. https://doi.org/10.1002/joc.6301

688 Walsh KJE, Fiorino M, Landsea CW, McInnes KL (2007) Objectively determined resolution689 dependent threshold criteria for the detection of tropical cyclones in climate models and 690 reanalyses. J Climate 20:2307-2314

691 Wang C, Liang J, Hodges K (2017) Projections of tropical cyclones affecting Vietnam under 692 climate change: downscaled HadGEM2-ES using PRECIS 2.1. Q J R Meteorol Soc 143: 693 1844-1859. https://doi.org/10.1002/qj.3046

694 WMO (1966) Regional Association V (South-West Pacific) Abridged Final Report of the Fourth 695 Session. WMO-No. 187. RP.69. World Meteorological Organization. 696 https://library.wmo.int/doc_num.php?explnum_id=7995. Accessed 8 September 2020.

697 Wu L (2012) Possible linkage between the monsoon trough variability and the tropical cyclone 698 activity over the western North Pacific. Mon Wea Rev 140:140-150. 699 https://doi.org/10.1175/MWR-D-11-00078.1

700 Yoshimura J, Sugi M, Noda A (2006) Influence of greenhouse warming on tropical cyclone 701 frequency. J Meteor Soc Japan 84:405-428. https://doi.org/10.2151/jmsj.84.405

702 Zeng X, Zhao M, Dickinson RE (1998) Intercomparison of bulk aerodynamic algorithms for the 703 computation of sea surface fluxes using TOGA COARE and TAO data. J Climate 11: 628704 2644. https://doi.org/10.1175/1520-0442(1998)011<2628:IOBAAF>2.0.CO;2 
Zhang W, Villarini G, Vecchi GA, Murakami H (2019) Rainfall from tropical cyclones: high-

706 resolution simulations and seasonal forecasts. Clim Dyn 52:5269-5289.

707 Zhao M, Held IM, Lin SJ (2012) Some counterintuitive dependencies of tropical cyclone 708 frequency on parameters in a GCM. J Atmos Sci 69: 2272-2283. $709 \quad$ https://doi.org/10.1175/JAS-D-11-0238.1

710

\section{Figure Captions}

712 Fig. 1 Map showing the geographic extent of the model domain. Shadings indicate surface model 713 elevation expressed in meters above mean sea level. The area enclosed by the dashed line covers the Philippine Area of Responsibility (PAR), the region being used by PAGASA for TC monitoring and in providing TC-related public advisories

Fig. 2 Annual frequency of TCs that existed in the PAR during the period from 1981 to 2010 based on the JMA best track data, ERAI, and the five ERAI-driven RegCM4 simulations using different CPS. The box and whiskers shown on the right side of the plot are also provided to depict various characteristics of the annual TC frequency for the entire period; the box limits correspond to the interquartile range, the whiskers cover the range, and the horizontal line inside the boxes marks the mean

Fig. 3 TC tracks spatial density maps based on a JMA observations, b ERAI, and $\mathbf{c}-\mathbf{g}$ the five CPS RegCM4 simulations. The spatial densities are obtained by taking the total number of TCs that existed in each of the $2^{\circ} \times 2^{\circ}$ grid box during the period 1981-2010; only those TCs that existed and/or entered the PAR are included

Fig. 4 Annual mean TC-associated rainfall (shadings) and percentage contribution to annual total rainfall (contours, units: \%) averaged over the 30-year period (1981-2010). Note that the 
minimum contour displayed is set at $5 \%$ with succeeding intervals of $5 \%$, and only those TCs that existed and/or entered the PAR are included

Fig. 5 Monthly average TC frequency over the PAR obtained from the JMA best track data, ERAI, and the five RegCM4 simulations using different CPS during the period 1981-2010

Fig. 6 Seasonal tracks of TCs that existed in the PAR based on a JMA best track data, b ERAI, and $\mathbf{c}-\mathbf{g}$ the five RegCM4 simulations covering the period 1981-2010. The three-month seasons used are January to March (JFM), April to June (AMJ), July to September (JAS), and October to December (OND). Colors correspond to the TC categories operationally being used by PAGASA namely, Tropical Depression (TD), Tropical Storm (TS), Severe Tropical Storm (STS), Typhoon (TY), and Super Typhoon (STY)

Fig. 7 Probability density functions (PDFs) fitted from the TC-lifetime highest 6-hourly MWS of the JMA observations, ERAI, and the RegCM4 simulations. The TCs considered are only those that existed in the PAR during the period from 1981 to 2010

Fig. 8 Box plots showing the time spent (expressed in hours) of all TCs that existed in the PAR from 1981 to 2010 over a the entire domain and $\mathbf{b}$ inside the PAR. The boxes cover the interquartile range while the whiskers correspond to the $10^{\text {th }}$ and $90^{\text {th }}$ percentiles; the horizontal line inside the boxes marks the mean

Fig. 9 Climatological mean vertical wind shear (shadings) and positive $850-\mathrm{hPa}$ relative vorticity (contours; $\times 10^{-6} \mathrm{~s}^{-1}$ ) during JAS based on a ERAI and b-f RegCM4 simulations

Fig. 10 Climatological mean 700-hPa relative humidity (shadings), 500-hPa geopotential heights (contours), and 850-hPa winds (vectors) during JAS based on a ERAI and b - f RegCM4 750 
751 Table 1. Summary of the RegCM4 experiments conducted in this study and their convective

752 parameterization scheme features.

\begin{tabular}{|c|c|c|c|}
\hline $\begin{array}{l}\text { Experiment } \\
\text { Name }\end{array}$ & $\begin{array}{l}\text { Convective } \\
\text { Parameterization }\end{array}$ & Trigger & Entrainment \\
\hline EM & $\begin{array}{l}\text { Emanuel scheme } \\
\text { (Emanuel 1991) }\end{array}$ & $\begin{array}{l}\text { Buoyancy exceeds } \\
\text { cloud base level }\end{array}$ & $\begin{array}{l}\text { Sub-cloud scale model } \\
\text { variable on buoyancy } \\
\text { of parcel }\end{array}$ \\
\hline GR & $\begin{array}{l}\text { Grell scheme (Grell } \\
\text { 1993) }\end{array}$ & $\begin{array}{l}\text { Updraft reaches moist } \\
\text { convection level }\end{array}$ & $\begin{array}{l}\text { Single cloud model at } \\
\text { the bottom }\end{array}$ \\
\hline $\mathrm{KF}$ & $\begin{array}{l}\text { Kain-Fritsch scheme } \\
\text { (Kain and Fritsch 1990) }\end{array}$ & $\begin{array}{l}\text { Perturbation based on } \\
\text { low-level vertical } \\
\text { motion }\end{array}$ & $\begin{array}{l}\text { Variable to buoyancy } \\
\text { of the air parcel }\end{array}$ \\
\hline $\mathrm{TE}$ & $\begin{array}{l}\text { Tiedtke scheme (Tiedtke } \\
\text { 1996) }\end{array}$ & $\begin{array}{l}\text { Moisture convergence } \\
\text { closure }\end{array}$ & $\begin{array}{l}\text { Moisture convergence } \\
\text { under static condition }\end{array}$ \\
\hline GR-EM & $\begin{array}{l}\text { Grell over land and } \\
\text { Emanuel over the ocean } \\
\text { schemes }\end{array}$ & $\begin{array}{l}\text { Same as GR and EM } \\
\text { applied over land and } \\
\text { ocean, respectively }\end{array}$ & $\begin{array}{l}\text { Same as GR and EM } \\
\text { applied over land and } \\
\text { ocean, respectively }\end{array}$ \\
\hline
\end{tabular}

